\title{
A Scale-Aware Modeling Framework to Quantify Subsurface Geochemical Exports and River Water Quality
}

\author{
DipanKar Dwivedi ${ }^{1 *}$, CARl I STEEFEL $^{1}$, Michelle E $^{2}$ \\ NEWCOMER ${ }^{1}$, BHAVNA ARORA ${ }^{1}$, ILHAN ÖZGEN- \\ XIAN $^{1}$, PETER S NICO ${ }^{1}$, Boris FAYBISHENKO ${ }^{1}$, \\ BAPTISTE DAFFLON ${ }^{1}$, HARUKO M WAINWRIGHT $^{1}$, \\ PATRICIA M FOX ${ }^{1}$, KenNETH H Williams ${ }^{1}$, SUSAN \\ HUBBARD $^{1}$ \\ ${ }^{1}$ Earth Sciences Division, Lawrence Berkeley National \\ Laboratory, Berkeley, CA 94720 USA
}

To predict subsurface geochemical exports at the reach scale and downstream river water quality, we present a scaleaware modeling framework taking advantage of the versatility of artificial intelligence and physics-based modeling. Our overarching approach aims at developing a scaling relationship between multi-directional exchanges at the terrestrial-aquatic interfaces (TAIs) and characteristic watershed and river landform features (e.g., sinuosity and amplitudes of meanders, topography, residence times). To compute multi-directional exchanges at TAIs, we integrated a river chemistry module, RiverFlotran, with the flow and reactive transport code PFLOTRAN. To quantify subsurface geochemical exports, we carried out three-dimensional reactive flow and transport simulations for a 10-meander system in the East River (western Colorado, USA) watershed area (Figure 1). This area is located within a high elevation catchment of the Watershed Function Scientific Focus Area Site of Berkeley Lab. Simulation results demonstrated that multi-directional exchanges are being influenced by river

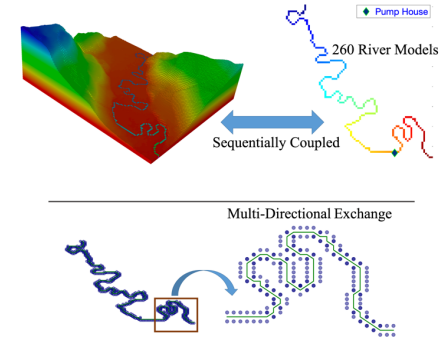

Figure 1: 10-meander modeling domain showing the RiverFlotran module accounting for multidirection exchanges. stage, bathymetry, and meander geometry, resulting in the formation of hot spots and hot moments of redox species. Results further demonstrated that scaling exponents typical for meanders are significantly different for oxidizing and reducing conditions. Efforts are underway to predict downstream river water quality of the more extensive East River system by making use of the scaling relationship developed in this study. 